\title{
Hygrothermal modelling of masonry blocks filled with thermal insulation
}

\author{
Balázs Nagy ${ }^{1, *}$ \\ ${ }^{1}$ Budapest University of Technology and Economics, Faculty of Civil Engineering, Department of \\ Construction Materials and Technologies, Mủegyetem rkp. 3. K.I.85., 1111 Budapest, Hungary
}

\begin{abstract}
Ceramic brick as building material has been used for thousands of years. Nowadays, the energy performance of new products has to meet rigorous requirements; therefore, in the design of new ceramic masonry blocks, building physical simulations are essential. The aim of this research is to evaluate existing masonry block shapes filled with different thermal insulation using conjugated heat and moisture transport finite element simulations with material properties measured in laboratory. The research compared four different internal structures: trapezoidal, triangular, rectangular, and with mixed shaped gaps according to existing masonry blocks. In the gaps, different thermal insulations were considered, such as mineral wool, expanded perlite and polyurethane foam. The research demonstrated that the perlite as filling material does not have a great effect on thermal conductivity comparing to unfilled blocks; however, polyurethane foam with an optimal internal structure can improve the thermal performance. Manufacturing inaccuracies in the materials' hygrothermal properties influences their performance, since a little difference in thermal conductivity has a noticeable impact on thermal transmittance, and it may result in underperformance according to regulations.
\end{abstract}

\section{Introduction}

In the $19^{\text {th }}$ century, ceramic bricks overcome as the most popular building material of industrial and commercial building. In the $20^{\text {th }}$ century, new masonry manufacturing procedures developed, such as the perforated fired clay bricks. The hollows in the masonry bricks reduced the amount of clay needed to manufacture the blocks, and improved the thermal performance too. Hollow bricks are lighter, therefore easier to handle, and usually used in single-wall constructions with finishes applied on the inside and outside. From the point of the present research, the development of hollow or filled masonry blocks is significant only after the 1960-s in Europe. Consequently the development of bricks occurred in two directions, after and regarding to the oil crisis in the 1970-s. The manufacturers started increasing the size of the holes, therefore decreasing the mass, as well as increasing the size of blocks to make the construction process more efficient and applying more porous material with smaller thickness [1]. In case of perforated bricks, the

\footnotetext{
*Corresponding author: nagy.balazs@epito.bme.hu
} 
location of holes has an effect on the thermal performance. For example a zigzag design results in a longer route for the heat transfer, therefore increases the thermal resistance. Beside the location, the different shapes of the holes also influence the heat and moisture transfer of the masonry blocks, therefore it has to be investigated.

Nowadays, the energy performance requirements are more and more rigorous, so manufacturers increase the thermal resistance of blocks with different fillings in the holes. Since the air can move in the holes, most of the solid insulating materials have lower thermal conductivities than the moving air's equivalent value in the gaps of the building blocks. Using fillings in the holes can lead to better thermal insulating capability [2].

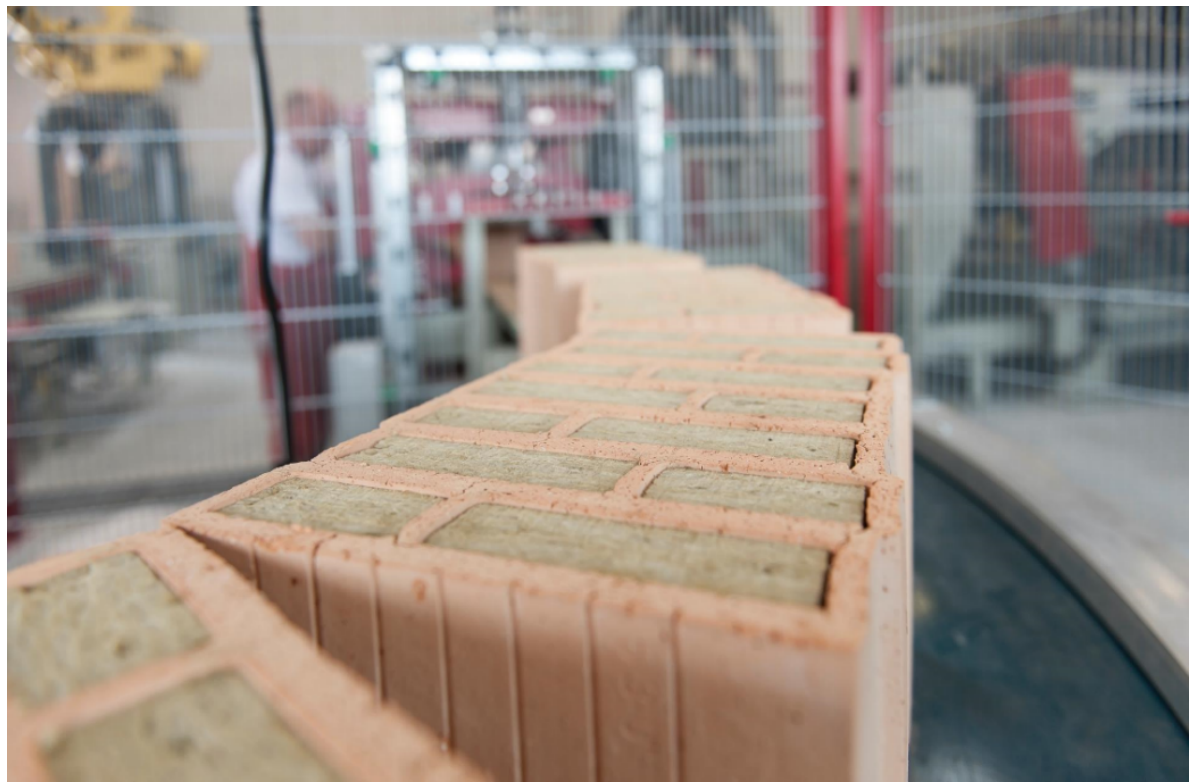

Fig. 1. Mineral wool filled masonry blocks [3].

Researchers in the past few years also started to investigate the thermal and hygrothermal behaviour of hollow and filled ceramic masonry blocks [1-2, 4-11] with different fillers and geometry. The presented research includes three of the most commonly used thermal insulation fillers in the industry, such as expanded perlite (Exp. Perlite), mineral wool (MW) and polyurethane foam (PUR foam). In this article four different fired clay masonry blocks with four different hollow shapes: rhombus, small rectangular, triangular and small rectangular, and big rectangular were investigated. The blocks are filled with the aforementioned three common thermal insulation materials.

\section{Conjugated heat and moisture transport modelling}

\subsection{Masonry block geometry}

Four different types of masonry blocks were modelled in 3D with different internal structures as shown in Fig. 2. a-d. Both geometry models represents an industry applied masonry block form. The dimensions of model ' $30 \mathrm{HS}$ ' are $30 \mathrm{~cm} \times 25 \mathrm{~cm} \times 25 \mathrm{~cm}$ and this block have mostly rhombus based internal structure. The dimension of model ' $38 \mathrm{~A}+$ ' are $38 \mathrm{~cm} \times 25 \mathrm{~cm} \times 25 \mathrm{~cm}$ and this block have only small, rectangular based internal hollows. '44T' marked block's dimensions are $44 \mathrm{~cm}$ x $25 \mathrm{~cm}$ x $25 \mathrm{~cm}$ and this block have triangle 
and rectangle shaped internal structure. The fourth block is called ' $44 \mathrm{~T}$ ', and it's have the same size as ' $44 \mathrm{~K}$ ' however with only big rectangular hollows. In the industry, $44 \mathrm{~T}$ is the most commonly used filled masonry block shape.
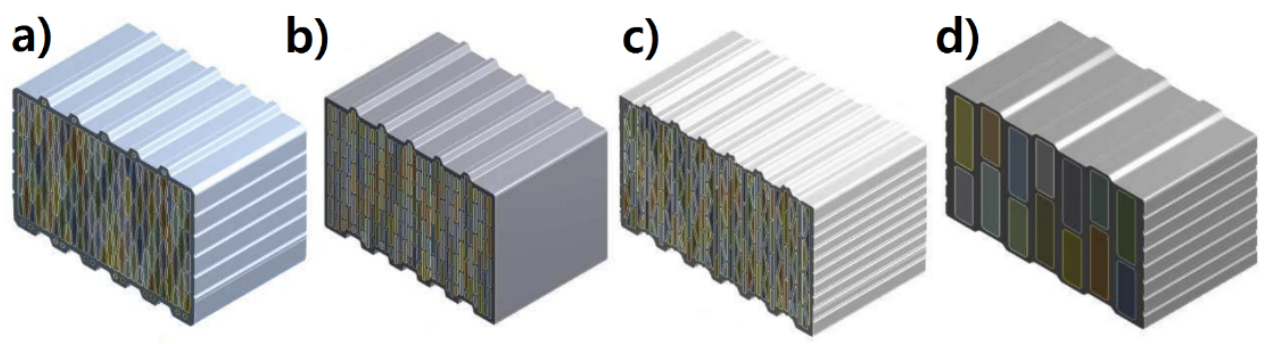

Fig. 2. Geometry models: a) 30HS; b) 38A+; c) 44K; d) $44 \mathrm{~T}$ masonry blocks.

\subsection{Partial differential equations}

In this paper, the physics of steady-state conjugated heat and moisture transport in porous media was considered. The partial differential equations (PDE) based on Künzel [12] solved using Comsol Multiphysics finite element method (FEM) software [13]. The PDE for steady-state heat transfer is the following:

$$
\begin{gathered}
\nabla \cdot \mathrm{q}=\mathrm{Q} \\
\mathrm{q}=-\left(\lambda_{e f f} \cdot \nabla \cdot \mathrm{T}+\mathrm{L}_{v} \cdot \delta_{p} \cdot \nabla \cdot\left(\phi \cdot \mathrm{p}_{s a t}\right)\right) \\
\lambda_{e f f}=\lambda \cdot \mathrm{e}^{f_{T}\left(T_{2}-T_{1}\right)} \cdot \mathrm{e}^{f_{\psi}\left(\psi_{2}-\psi_{1}\right)}
\end{gathered}
$$

where $\nabla$ is nabla vectorial differential operator, $\mathrm{q}$ is heat flux $\left[\mathrm{W} / \mathrm{m}^{2}\right]$, Q is heat source $\left[\mathrm{W} / \mathrm{m}^{3}\right], \lambda_{\text {eff }}$ is temperature and moisture dependent effective thermal conductivity [W/mK] according to EN ISO 10456:2007 [14], T is temperature [K], $\mathrm{L}_{\mathrm{v}}$ is latent heat of evaporation of water $[\mathrm{J} / \mathrm{kg}], \delta_{\mathrm{p}}$ is vapour permeability $[\mathrm{g} / \mathrm{msPa}], \varphi$ is relative humidity $[-]$ and $\mathrm{p}_{\text {sat }}$ is the saturation pressure of water vapour $[\mathrm{Pa}] . \mathrm{f}_{\mathrm{T}}$ is the temperature conversion coefficient $[1 / \mathrm{K}]$, $f_{\psi}$ is the moisture conversion coefficient $\left[\mathrm{m}^{3} / \mathrm{m}^{3}\right]$, when $T_{2}$ is the effective, $T_{1}$ is the declared temperature $[\mathrm{K}]$ and $\psi_{2}$ is the effective, $\psi_{1}$ is the declared volumetric moisture content. The PDE for moisture transfer is the following:

$$
\begin{gathered}
\nabla \cdot \mathrm{g}=\mathrm{G} \\
\mathrm{g}=-\left(\xi \cdot \mathrm{D}_{w} \cdot \nabla \cdot \phi+\delta_{p} \cdot \nabla \cdot\left(\phi \cdot \mathrm{p}_{s a t}\right)\right) \\
\xi=\frac{\partial \mathrm{w}}{\partial \phi}
\end{gathered}
$$

where $\mathrm{g}$ is moisture flux $\left[\mathrm{kg} / \mathrm{m}^{2} \mathrm{~s}\right], \mathrm{G}$ is moisture source $\left[\mathrm{kg} / \mathrm{m}^{3} \mathrm{~s}\right], \xi$ is differential moisture capacity $\left[\mathrm{kg} / \mathrm{m}^{3}\right], \mathrm{D}_{\mathrm{w}}$ is moisture diffusivity $\left[\mathrm{m}^{2} / \mathrm{s}\right]$ and $\mathrm{w}$ is the moisture content $\left[\mathrm{kg} / \mathrm{m}^{3}\right]$ according to the hygroscopic sorption isotherms of the materials.

\subsection{Boundary conditions}

The boundary conditions for adiabatic conditions (eq. 7) and for heat flux (eq. 8) are the following: 


$$
\begin{gathered}
-\mathbf{n} \cdot \mathrm{q}_{0}=0 \\
-\mathbf{n} \cdot \mathrm{q}_{0}=\left(h_{c}+h_{r}\right)\left(T_{\text {air }}-T\right)
\end{gathered}
$$

where $\mathrm{q}_{0}$ is the inward heat flux $\left[\mathrm{W} / \mathrm{m}^{2}\right], \mathrm{h}_{\mathrm{c}}$ is the wind speed dependent convective and $\mathrm{h}_{\mathrm{r}}$ is the temperature dependent radiative heat transfer coefficient $\left[\mathrm{W} / \mathrm{m}^{2} \mathrm{~K}\right]$ according to ISO 6946:2007 [15]. $\mathrm{T}_{\text {air }}$ is internal air temperature in steady-state conditions set to $293.15 \mathrm{~K}$ and external temperature set to $271.15 \mathrm{~K}$ according to MSZ 24140:2015 [16].

According to [1 and 13], the moisture transfer boundary conditions are the following:

$$
\begin{gathered}
-\mathbf{n} \cdot \mathrm{g}_{0}=0 \\
-\mathbf{n} \cdot \mathrm{g}_{0}=\beta_{p} h_{c}\left(\phi_{\text {air }} \cdot \mathrm{p}_{\text {sat }}\left(T_{\text {air }}\right)-\phi \cdot \mathrm{p}_{\text {sat }}(T)\right)
\end{gathered}
$$

where $\beta_{\mathrm{p}}$ constant is $7.7 \cdot 10^{-9}\left[\mathrm{kgK} / \mathrm{WsPa}\right.$ which if multiplied by $\mathrm{h}_{\mathrm{c}}$ convective heat transfer coefficient gives the moisture transfer coefficient $\left[\mathrm{kg} / \mathrm{m}^{2} \mathrm{sPa}\right] . \varphi$ is the relative humidity, internally set to 0.65 and externally 0.9 was used respecting MSZ 24140:2015 [16].

\subsection{Material properties}

The measurements of the hygrothermal material properties were performed at the Budapest University of Technology and Economics Department of Construction Materials and Technologies Laboratory of Building Physics detailed in [1]. Each materials' $\varrho$ density, $\lambda$ thermal conductivity and $\delta$ vapour diffusion coefficient were measured, while $c_{p}$ specific heat capacity, $f_{T}$ and $f_{\psi}$ conversion factors are from ISO 10456:2007 [14]. The hygrothermal properties listed in Table 1.

Table 1. Hygrothermal material properties.

\begin{tabular}{|l|c|c|c|c|c|c|}
\hline \multirow{3}{*}{ Material } & \multicolumn{7}{|c|}{ Hygrothermal properties } \\
\cline { 2 - 7 } & $\begin{array}{c}\mathbf{\rho} \\
{\left[\mathbf{k g} / \mathbf{m}^{3}\right]}\end{array}$ & $\begin{array}{c}\boldsymbol{\lambda} \\
{[\mathbf{W} / \mathbf{m K}]}\end{array}$ & $\begin{array}{c}\mathbf{c}_{\mathbf{p}} \\
{[\mathbf{J} / \mathbf{k g K}]}\end{array}$ & $\begin{array}{c}\mathbf{f}_{\mathbf{T}} \\
{[\mathbf{1} / \mathbf{K}]}\end{array}$ & $\begin{array}{c}\mathbf{f}_{\boldsymbol{\psi}} \\
{\left[\mathbf{m}^{\mathbf{3}} / \mathbf{m}^{3}\right]}\end{array}$ & $\begin{array}{c}\boldsymbol{\delta} \\
{[\mathbf{g} / \mathbf{m s M P a}]}\end{array}$ \\
\hline Fired clay & 1500 & 0.35 & 800 & 0.001 & 10 & 0.0133 \\
\hline Exp. Perlite & 90 & 0.05 & 900 & 0.0035 & 3 & 0.1000 \\
\hline MW & 75 & 0.031 & 1000 & 0.0045 & 4 & 0.1538 \\
\hline PUR foam & 35 & 0.024 & 1400 & 0.0055 & 6 & 0.0033 \\
\hline
\end{tabular}

Hygroscopic sorption properties were measured between the range of $0-97 \%$ relative humidity according to ISO 12571:2013 [17] detailed in [1]. Free water saturation point obtained by immersing the samples in water for 28 days. The results shown in Table 2.

Table 2. Water content $\left[\mathrm{kg} / \mathrm{m}^{3}\right]$ according to relative humidity.

\begin{tabular}{|l|c|c|c|c|c|}
\hline \multirow{2}{*}{ Material } & \multicolumn{5}{|c|}{ Relative Humidity [1] } \\
\cline { 2 - 6 } & $\mathbf{0 . 2 5}$ & $\mathbf{0 . 5}$ & $\mathbf{0 . 7 5}$ & $\mathbf{0 . 9 7}$ & $\sim \mathbf{1}$ \\
\hline Fired Clay & 0.36 & 0.76 & 2.65 & 23.34 & 355.68 \\
\hline Exp. Perlite & 0.05 & 0.08 & 0.10 & 0.38 & 1.42 \\
\hline MW & 0.06 & 0.09 & 0.11 & 0.49 & 1.92 \\
\hline PUR foam & 0.21 & 0.46 & 0.69 & 0.79 & 0.84 \\
\hline
\end{tabular}




\subsection{Calculating equivalent thermal conductivity}

From the simulated results, the equivalent thermal conductivities of the masonry blocks were calculated using the following formula:

$$
\lambda_{e q}=\frac{\mathrm{q} \cdot \mathrm{A}}{d \cdot \Delta T}
$$

where $\mathrm{q}$ is the average heat flux measured on the internal side of the masonry block $\left[\mathrm{W} / \mathrm{m}^{2}\right], \mathrm{A}$ is the internal surface of the masonry block $\left[\mathrm{m}^{2}\right], \mathrm{d}$ is the thickness of the masonry block $[\mathrm{m}]$ and $\Delta \mathrm{T}$ is the temperature difference between the internal and external temperature $[\mathrm{K}]$.

\section{Results}

\subsection{Equivalent thermal conductivity}

The steady-state equivalent thermal conductivities of the thermal insulation filled masonry blocks are shown in Fig. 3. It is notable that both insulation fillers improved the thermal conductivity of the masonry blocks. Small hollows shows the same pattern in improvement due to better thermal insulation fillers. There is no significant difference in the thermal conductivities between ' $38 \mathrm{~A}+$ ' and ' $44 \mathrm{~K}$ ' models, when they were filled with insulations. However ' $44 \mathrm{~T}$ ' performed best when filled, this model improved the less with PUR foam filler compared to mineral wool filler, but also this model improved the most changing expanded perlite to mineral wool. It's observable that the shape of the hollows plays key role in the thermal insulation capability of the masonry blocks.

Masonry blocks can improve with PUR foam up to $31 \%$ compared to expanded perlite filler, and up to $19 \%$ compared to mineral wool. With expanded perlite and mineral wool fillers, masonry blocks containing smaller hollows performs almost the same thermal conductivity values. Comparing the $44 \mathrm{~cm}$ thick bricks, '44T', which have large rectangular hollows have lower equivalent thermal conductivity than ' $44 \mathrm{~K}$ ', which have small rectangular and triangular hollows.

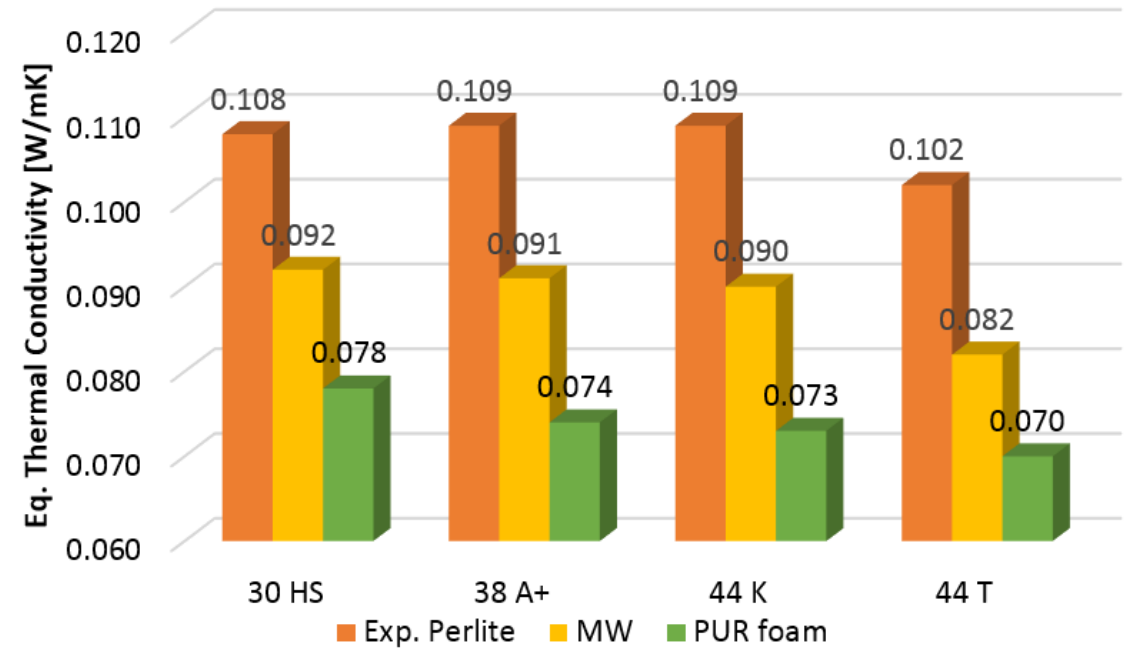

Fig. 3. Equivalent thermal conductivity of the filled masonry blocks. 
A 3D surface coloured representation is obtained from each simulation showing the temperature and relative humidity distribution in the bricks. Mineral wool filled '44T' model shown in Fig. 4. The results were also obtained in the bisector of the masonry blocks.
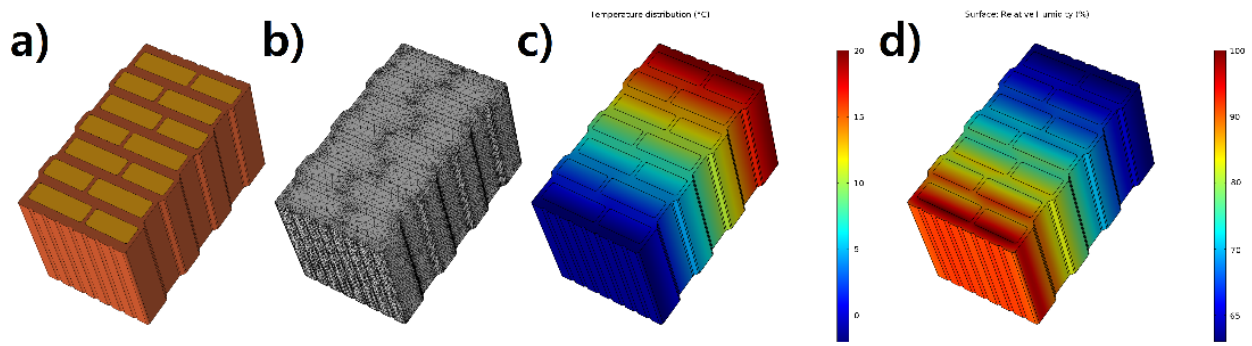

Fig. 4. Hygrothermal simulation of the ' $44 \mathrm{~T}$ ' model filled with mineral wool: a) geometry; b) Finite element mesh; c) Temperature distribution; d) Relative humidity distribution.

\subsection{Temperature distribution}

3D numerical simulated steady-state temperature results along the bisector line showed in Fig. 5. The graph also contains the simplified 1D calculated temperature distribution according to EN ISO 13788:2012, where one layer and the equivalent thermal conductivity showed in Fig. 3. was used. Using this simple one layer model calculation, the temperatures can calculated only on the surfaces. The difference between the temperatures calculated using simplified 1D calculation and 3D numerical simulation is very significant (see Fig. $5)$.

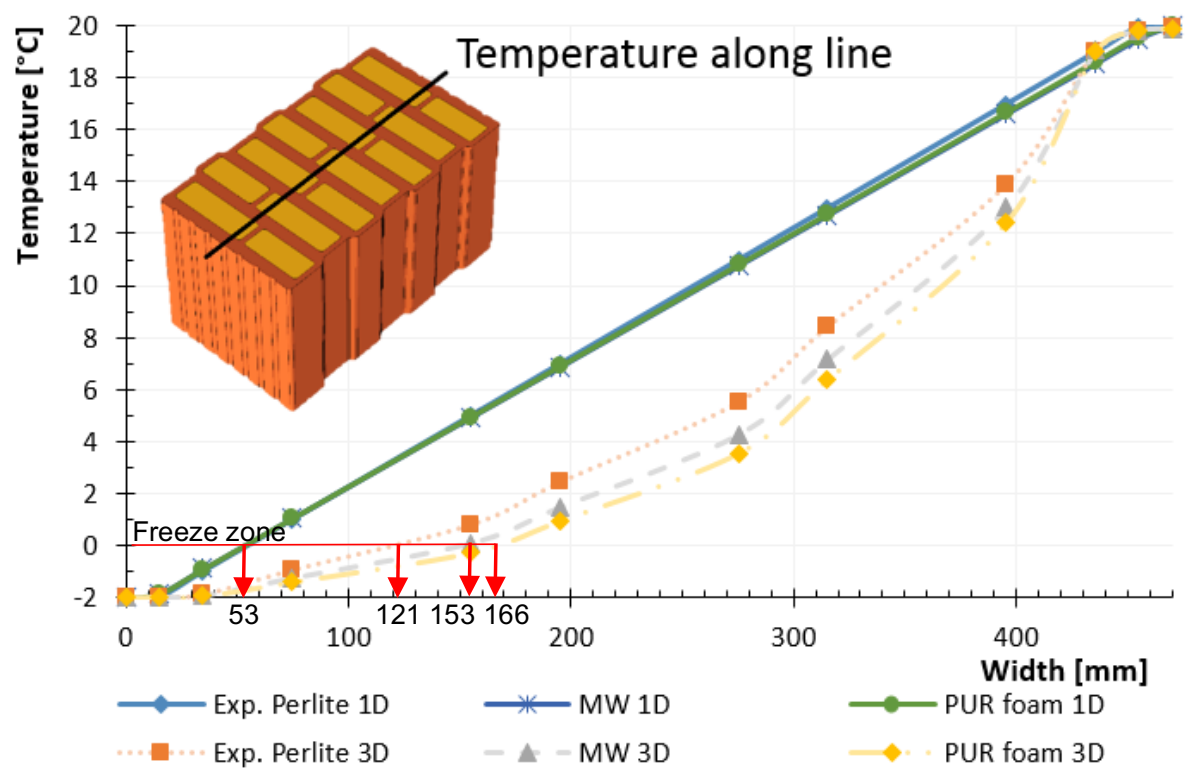

Fig. 5. Temperature along line comparison of $1 \mathrm{D}$ calculated and $3 \mathrm{D}$ simulated results.

If the temperature change assumed to be linear in the filled masonry blocks between the calculated surface temperatures, the simulated temperature distribution, in all cases, lower than the 1D obtained results. Simulated results shows remarkably thicker external side zone, $53 \mathrm{~mm}$ (All fillers) compared to $121 \mathrm{~mm}$ (Exp. perlite), $153 \mathrm{~mm}$ (MW) and $166 \mathrm{~mm}$ 
(PUR foam) respectively, where the masonry block can freeze. There is also significant freeze zone increment due to different fillers, better insulating fillers have wider freeze zone. In the inside of the masonry blocks, simulated results can differ up to $7.2{ }^{\circ} \mathrm{C}$. The shape of the graphs differs too compared to each other, $1 \mathrm{D}$ is linear, because both fired clay and the thermal insulation filler is calculated in one layer using the filled blocks' overall equivalent thermal conductivity, and also 1D calculation cannot take into account the geometric variability. Simulated results fits to an exponential curve.

\subsection{Vapour pressure distribution}

From the relative humidity along the bisector line, partial vapour pressure can be calculated using the water vapour saturation pressure depending on the temperature. Fig. 6 . shows the partial vapour pressure calculated from the simulations and from 1D calculation (standard Glaser method) according to ISO 13788:2012 using each masonry blocks' equivalent vapour diffusion coefficient.

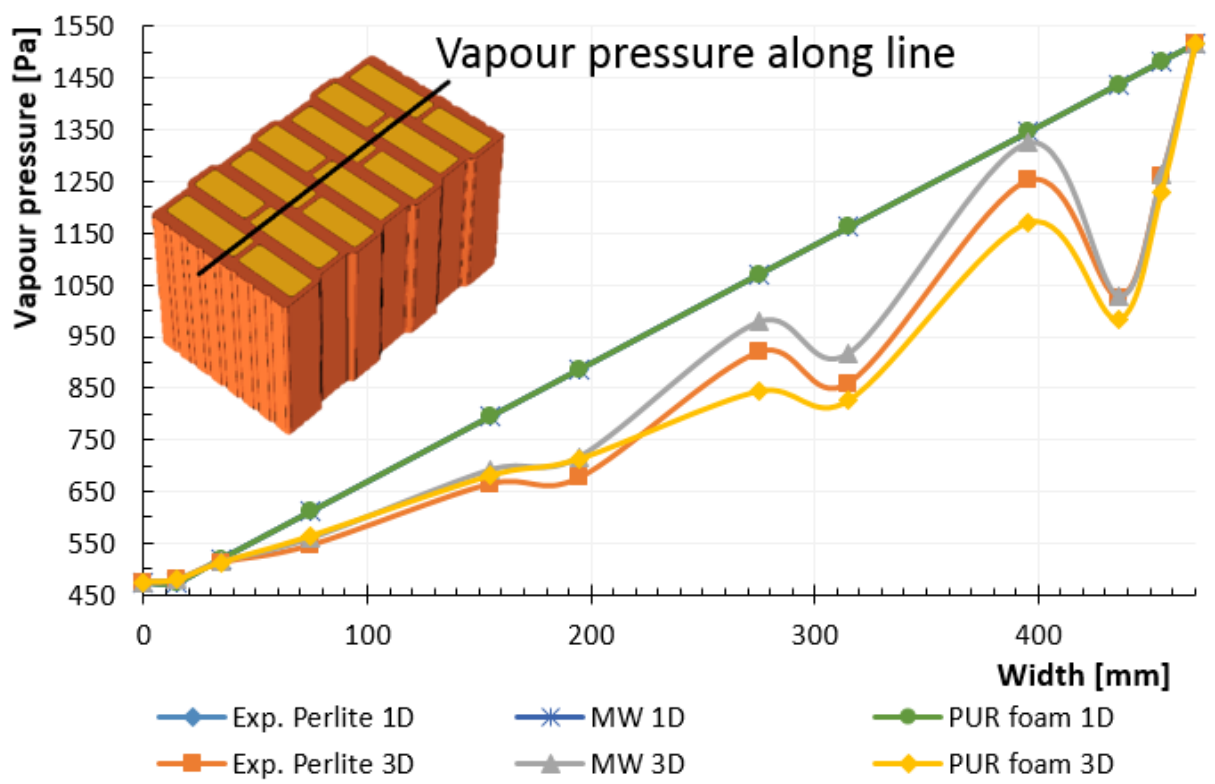

Fig. 6. Vapour pressure along line comparison of $1 \mathrm{D}$ calculated and $3 \mathrm{D}$ simulated results.

The shape of the curves are significantly different, while $1 \mathrm{D}$ calculated vapour pressure is linear in the one and only layer, while the simulated vapour pressure is not even decreasing steadily due to the changing materials along the line. It can be observed that expanded perlite's and mineral wool's vapour pressure curve remains the same distance to each other along the brick, but PUR foam filled brick's vapour pressure curve is going below the mineral wool's curve around the half of the block. This phenomena can be explained by the different hygroscopic sorption behaviour of the PUR foam, and the other two insulation, which is observable in Table 2 too. PUR foam is better thermal insulation, which results lower temperature distribution along line (see Fig. 5), but higher relative humidity, which means higher vapour pressure. 


\section{Conclusions}

In this paper, four different geometries of masonry blocks with three different thermal insulation fillers were examined. The equivalent thermal conductivity of the building blocks shows that fillers with lower thermal conductivity results in lower overall results, however the improvement is not linear. Only the '44T' block is recommended to use with perlite filler, since there is not worth using fillers if they not lowering enough in the masonry blocks' thermal conductivity. PUR foam can significantly lower the values of all building blocks. Larger rectangular hollows perform better when they are filled with insulation than small rectangular, triangular or trapezoidal hollows. Filling smaller hollows is beneficial, when the filler have good thermal insulating capability and the shape of the hollows are well designed.

Steady-state condition simulations of temperature and vapour pressure distribution in the ' $44 \mathrm{~T}$ ' geometry along the bisector line showed that there can be up to $7.2{ }^{\circ} \mathrm{C}$ temperature and significant partial vapour pressure difference inside the blocks regarding the fillers compared to simplified one layer model results. The use of hydrophobic filler materials at least till $95 \%$ relative humidity is essential. Simulations also showed that the outer one-third of the insulation filled masonry blocks' width is exposed to the risk of freezing, which includes two or three thermal insulation filled hollows depending on the filler material. With simplified one layer model, freeze zones can not be examined properly. Freezing can damage the not suitable filler materials and spoil their hygrothermal performance, therefore numerical simulation is advised, when complex inhomogeneous elements, such as insulation filled masonry blocks are investigated.

\section{References}

1. B. Nagy, E. Tóth, RILEM Proceedings PRO 112, 279-288 (2016)

2. B. Nagy, M. Orosz, Applied Mechanics and Materials 797, 174-181 (2015)

3. http://clay-wienerberger.com (January, 2018)

4. M. Zukowski, G. Haese, Energy and Buildings 42, 1402-1408 (2010)

5. J. Zach, J. Hroudova, M. Sedlmajer, Proceedings of the 2nd Central European Symposium on Building Physics, 169-174 (2013)

6. J. Kočí, J. Maděra, M. Jerman, R. Černý, Proceedings of the 2nd Central European Symposium on Building Physics, 635-639 (2013)

7. Y, Pavlík, M. Jerman, A. Trník, V. Kočí, R. Černý, J. Build.Physics 37, 436-448 (2014)

8. A.B.T.P. Setty, S. Shaik, Proceedings of the 4th International High Performance Buildings Conference at Purdue, 3416 (2016)

9. J. Zach, V. Novák, Procedia Engineering 151, 206-2013 (2016)

10. J. Wernery, A. Ben-Ishai, B. Binder, S. Brunner, Energy Procedia 134, 490-498 (2017)

11. J. Li, X. Meng, Y. Gao, W. Mao, T. Luo, L. Zhang, Case Studies in Thermal Engineering 11, 62-70 (2018)

12. H. Künzel, IRB Verlag, 102 (1995)

13. Comsol Multiphysics 5.3 Heat transfer module user's guide (2017)

14. ISO 10456 (2007)

15. ISO $6946(2017)$

16. MSZ 24140 (2015)

17. ISO $12571(2013)$

18. ISO 13788 (2012) 